\title{
The powdery mildew disease of rubber (Oidium heveae) mainly controlled by the winter temperature in the Xishuangbanna, China
}

Deli Zhai ( $\nabla$ deliaxtbg@gmail.com )

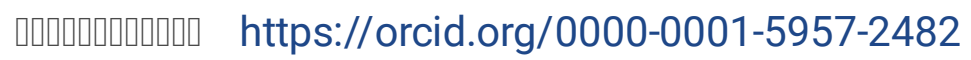

\section{Philippe Thaler}

CIRAD

\section{Yiqi Luo}

Northern Arizona University

Jianchu Xu

Kunming Institute of Botany Chinese Academy of Sciences https://orcid.org/0000-0002-2485-2254

Research article

Keywords: rubber plantation, Oidium heveae, Partial Least Square (PLS) regression,winter warming, phenology

Posted Date: July 12th, 2019

DOI: https://doi.org/10.21203/rs.2.11275/v1

License: (9) (1) This work is licensed under a Creative Commons Attribution 4.0 International License. Read Full License 


\section{Abstract}

Background: Rubber powdery mildew disease (Oidium heveae) is a serious threat to the natural rubber production in some rubber developing regions of the world. Many factors affect the powdery mildew disease. As many of these influencing factors found in previous studies are strongly correlated, unraveling their effects and their relative importance is a challenge. We assessed the three main groups of factors: temperature variables, the timing of leaf phenologies, and the duration of leaf development. In total, we investigated the effects of forty-one factors on the infection rate of powdery mildew of rubber trees (Hevea brasiliensis) by using Partial Least Squares (PLS) regression methods over 9-year records (2003-2011). Results: Among these factors, we found that the most influential variables were the temperature variables (winter and spring mean temperature, and daily temperature differences in winter) and the duration of leaf development to maturation, from copper brown stage to leaf aging, which explained $72 \%$ and $58 \%$ of the variations in the infection rate. We found the controlling role of winter mean temperature, for the first time, on the infection rate of powdery mildew, and the duration of leaf maturation was also influenced by the winter mean temperature. Conclusions: The controlling role of winter temperature may have directly increase the infection rate when winter temperature is high, and indirectly increase the infection rate through the prolongation of the leaf maturation duration, although the duration itself, from copper brown to leaf aging had smaller influences. We detected a warming trend of the winter temperatures from 2003 to 2011, which indicates that the rubber plantations will experience increasing of infection rate of powdery mildew if the winter warming continues.

\section{Background}

Powdery mildew disease of rubber, caused by the Oidium heveae, is a major threat for rubber plantations (Hevea brasiliensis) in tropical China (Liyanage et al., 2018). The powdery mildew disease mainly affects immature leaves, flowers, and other immature tissue of rubber trees in the refoliation season, and the disease could result in a up to $45 \%$ losses of rubber latex production (Liyanage et al., 2018). The outbreaks of this disease have affected the livelihoods of the involved farmers by two aspects: one is the economic loss caused by the powdery mildew through rubber latex reduction and use of chemical fungicides, the other is the ecological consequences to environment (Li et al., 2016).

To minimize economic losses caused by the powdery mildew, chemical fungicides and experience-based monitoring and assessments are two main solutions to control this disease (Liyanage et al., 2018; PPRI, 1985; Yu et al., 1985). Compared to the experience-based monitoring and assessments, applying chemical fungicides (normally through spraying sulfur) is more common, and the decision on when to spray is often made by the experienced workers through monitoring both the phenology of rubber and local meteorology, based on the assumption that these two are the main factors influencing the infection of powdery mildew (PPRI, 1985; Yu et al., 1985). Therefore, phenology of rubber trees and local meteorology during the refoliation period are frequently monitored to forecast the infection of powdery mildew (PPRI, 1985; Yu et al., 1985). The government in the main rubber cultivation region of 
Xishuangbanna (Yunnan province) has even developed an agro-meteorological service to forecast the powdery mildew based on the monitoring of rubber phenology and local meteorology.

A recent study investigating the responses of infection rate of powdery mildew to the daily climatic variables has demonstrated that temperatures during both defoliation and refoliation periods influence the infection rate (Zhai et al., under review). In that research, it indicated the importance of the timing of the leaf phenological phases to the infection rate of powdery mildew (Zhai et al., under review). In another research, we found that such timing was influenced by monthly climatic variables (Zhai et al., 2017). The phenology of rubber trees can be described by five phenological stages in the refoliation season:

budburst, copper brown (emergence of leaves), color changing (starting of the expansion phase, hanging leaves), light green (full expansion phase, still hanging), and leaf aging (leaf thickening and straightening) (Fig. 1) (Zhai et al., 2019). The leaves are more easily infected by the powdery mildew disease from copper brown to light green periods, i.e. during their expansion phase (Shao and Hu, 1984). However, it is still unclear how the powdery mildew disease responds to the timing of these phenological stages. Additionally, other studies found that shorter duration from budburst to leaf aging could decrease the leaf susceptibility to powdery mildew (Xiao, 2010; Yu et al., 1980; Zhang et al., 2009). Therefore, the climatic variables, the timing of phenologies, and the duration of leaf development between phenological stages could influence the powdery mildew infection, however, it is unclear which factors are more important and how these factors interact to affect the powdery mildew infection. Therefore, any studies focusing on single factor to predict the powdery mildew infection may not be accurate enough.

Therefore, we hypothesize that the timing of phenologies, the duration of leaf development, and climatic variables have a joint effect on the infection rate of powdery mildew. Following this hypothesis, we ask and try to answer the following three questions: (1) which factors (e.g. timing of phenologies, duration of leaf development between phenological stages, and climatic variables) affect the infection rate of powdery mildew; (2) which factors are more important to explain the variations of infection rate; (3) whether and how are the effects of the above identified influencing factors on the infection rate of powdery mildew dependent upon each other?

\section{Methods}

\section{Study area}

Xishuangbanna, one of the sub-optimal regions for rubber cultivation in the Southeast Asia, is located at the northern edge of the Asian tropical zone (Yu et al., 2014; Zhu et al., 2006) (Fig. S1). Compared to the optimal environment of rubber cultivation regions in the humid tropics, the climate in Xishuangbanna is cooler and drier (Priyadarshan, 2011; Yu et al., 2014). There are three seasons in Xishuangbanna (Cao et al., 2006; Zhang and Cao, 1995): cool-dry season (November-February), hot-dry season (March-April), and rainy season (May-October). The cool-dry season is featured for the lowest temperature in a year and little rainfall. During the cool-dry season, the rubber trees experience leaf defoliation (or wintering, 
from early December to middle of January) and refoliation (from end of January to end of March) (Zhai et al., 2019). We studied the powdery mildew disease of rubber trees in a state-owned farm (the sixth branch of Jinghong Farm) located near Jinghong City, Xishuangbanna Prefecture, Yunnan Province $\left(21^{\circ} 48 \mathrm{~N}, 100^{\circ} 46 \mathrm{E}\right)$. This state farm has 1813 hectares of rubber plantations, and the major clones are RRIM600, GT1, PR107, and YUNYAN1.

\section{Data collections}

From 2003 to 2011, the rubber powdery mildew infection rate was observed with an interval of 3 days from the end of January to the end of March. The phenology of the rubber trees was also observed from mid-January to mid-April with an interval of 3 days. Fifteen observation sites with five sub-observation sites for each site were selected in Jinghong State farm, and all of these sites recorded both phenology and powdery mildew disease data. Twenty trees were selected and marked at each sub-observation site. One whorl of rubber leaves was randomly collected from each of these 20 trees, and $15 \sim 60$ leaves were collected from each whorl, which led to $300 \sim 1200$ leaves in each sub-observation site. The percentage of leaves infected by powdery mildew was recorded on each sub-observation site. The infection rate of the powdery mildew was then calculated in each sub-observation site (Xiao, 2010).

The refoliation was characterized by 5 stages (budburst (bb for short), copper brown (cb), color changing (cc), light green (lg), and leaf aging (la)). The timing of each phenological stage is divided in 4 periods according to the percentage of leaves in each stage: $5 \%, 10 \%, 20 \%$, and peak (ie. bb_5, bb_10, bb_20). The duration of leaf development between the five phenological stages (i.e. length_bb_cb, length_bb_cc) refers to the days required from $5 \%$ of a preceding stage (i.e. budburst) to the peak of the next phenological stages (i.e. copper brown, color changing), which reflect the leaf development. The duration of leaf development of a given stage was measures as the days required from $5 \%$ to peak of each stage (i.e. length_bb, length_cb).

Daily maximum, minimum, and mean temperatures between 2003 and 2011 were collected from the National Meteorological Information Center of China (http://data.cma.cn/). The daily temperature difference (TD) was calculated from daily maximum and minimum temperatures.

Our previous study showed that the mean temperature from 10 December to 21 January (recorded as Tmean1) and from 7 Feb to $15 \mathrm{Mar}$ (Tmean2), maximum temperature from 10 December to 21 January (Tmax1) and from 7 Feb to 15 Mar (Tmax2), and temperature difference from 6 December to 11 January (TD1) and from 23 Jan to 30 Mar (TD2) significantly affected the infection rate. Therefore, these six climatic variables were used as the independent factors (Zhai et al., under review).

\section{Statistical analysis}

Partial Least Square (PLS) regression was employed to analyze the responses of the infection rate of powdery mildew disease to both phenology-related variables (including twenty factors related to the 
timing of phenologies and fifteen factors related to the duration of leaf development) and climatic variables (including six climatic variables).

The PLS regression is used when independent variables (in this case twenty factors related to the timing of phenologies, fifteen factors related to durations of leaf development, and six climatic variables) are highly correlated, and the number of independent variables exceeds the number of dependent variables (Guo et al., 2013; Luedeling and Gassner, 2012). The PLS results produce two major outputs: the variable importance in the projection (VIP) statistic and standardized model coefficients. The VIP values reflect the importance of all independent variables for explaining the variations of the dependent (the infection rate of powdery mildew). Standardized model coefficients and their $95 \%$ confidence interval were used to interpret the strength and direction of the impacts of independent variables in the PLS model (Luedeling and Gassner, 2012). Independent variables with VIP $\geq 0.8$ and standardized coefficient confidence intervals significantly different from zero were considered important for explaining the infection rate of powdery mildew disease (Luedeling and Gassner, 2012; Yu et al., 2014). The positive value of the model coefficients and VIP $\geq 0.8$ was correlated to the increase of infection rate of powdery mildew. The negative model coefficients and VIP $\geq 0.8$ was correlated to the decrease of infection rate of the powdery mildew. The accuracy of the PLS model was evaluated with the root mean square error (RMSE) of the regression analyses.

Based on the VIP and model coefficients, we identified 23 factors that significantly influence the infection rate of powdery mildew. To assess the relative contributions of the above 23 factors to the infection rate of powdery mildew, these factors have been classified into three groups: climatic variables, timing of phenologies, and durations of leaf development. To decompose the variation of the infection rate of powdery mildew into fractions explained by the climatic variables, timing of phenologies, and durations of leaf development, we conducted a variance partitioning analysis based on redundancy analysis. The variation partitioning analysis was conducted using the 'varpart' function in the R package 'vegan' (Dixon, 2003). The PLS regression has also been employed to analyze the responses of the identified critical factor (i.e. length_cb_la) to daily climatical variables after the variation partitioning analysis.

All analyses were implemented in the $R$ programming language ( $R$ Core Team 2017). PLS analysis was mainly based on the 'pls' and 'chillR' package (Luedeling, 2017; Luedeling and Gassner, 2012; Mevik et al., 2016).

\section{Results}

\section{Factors affecting the infection rate of powdery mildew}

We identified 23 factors that significantly affected the infection rate of powdery mildew (Fig. 2). Among these 23 factors, there were 3 factors related to the timing of phenologies, 14 factors related to the duration of leaf development between phenological stages, and 6 factors related to climatic variables. 
Among the four developing levels of each stage, only three variables had significant effects: the timing of $5 \%$ level of copper brown, timing of peak level of light green and leaf aging (Fig. 2). Later start of the copper brown phase (later emergence of the leaves) resulted in a lower infection rate. Conversely, later peak of the light green and leaf aging phases (later growth and maturation peaks) resulted in higher infection rates (Fig. 2).

The PLS results demonstrated that almost all the factors related to the durations of leaf development between phenological stages (e.g. length_cb, length_cb_la) had a positive effect on the infection rate. This indicated that increasing the number of days required for leaf development would increase the infection rate.

The climatic variables (Tmean1, Tmax1, and TD1) in the defoliation season had a positive effect, while the climatic variables in the refoliation season had a negative effect. This indicated that increasing temperature in the defoliation period would increase the infection rate of powdery mildew, while increasing temperature in the refoliation period would decrease the infection rate of powdery mildew (Fig. 2).

Fig. 2 Results of Partial Least Squares (PLS) regression correlating infection rate of powdery mildew during 2003-2011 to fourty-one factors in three groups of timing of phenologies, duration of leaf development, and the climatic variables. In the upper panel, blue bars mean that VIP is above 0.8 , the threshold for variable importance. In the under panel, red bars correspond to important and negative model coefficients and VIP values are greater than 0.8 , while green bars indicate important positive relationships between infection rate of powdery mildew and the gray bars indicate no statistical significance.

\section{The infection rate of powdery mildew is determined by the joint effects of the temperature variables and the duration of leaf maturation (Length_cb_la, duration from copper brown to leaf aging)}

The variations identified by the PLS were grouped to three groups for the variation partitioning analysis. The variation partitioning analysis showed that the combination of the temperature variables (including Tmean1, Tmean2, and TD1) and the duration of leaf development to maturation (duration from copper brown to leaf aging, indicating the number of days required from copper brown stage to leaf maturation) were the two most important influential factors on the variation of the infection rate of powdery mildew among the forty-one studied variables (Fig. 2 \& Fig. 3). The temperature variables and the duration of leaf maturation could explain $76 \%$ of the observed variation in the infection rate of powdery mildew, among which $54 \%$ of the total variation was jointly explained by the both fractions (Fig. 3a). The joint effects of the temperature variables and the duration of leaf maturation on the infection rate of powdery mildew cannot be disentangled (Fig. 3a). 
The temperature variables and the duration of leaf maturation significantly explained $72 \%$ and $58 \%$ of the total variation in the infection rate of powdery mildew, respectively, with their unique exclusive explanations were $18 \%$ and $4 \%$, respectively (Fig. 3a). Therefore, the joint effects of temperature variables and the duration of leaf maturation were the main two factors influencing the infection rate of powdery mildew, with the duration of leaf maturation playing a lesser significant role.

Fig. 3 Variation partition analysis of the effects of timing of phenologies, duration of leaf development, and the climatic variables on the infection rate of powdery mildew (a), and the PLS results between (b) daily mean temperature, and (c) daily temperature difference from previous April to March and duration of leaf development ( from copper brown to leaf aging (length_cb_la)), and also the PLS results between (d) daily mean temperature, and (e) daily temperature difference and infection rate of powdery mildew during 2003-2011. See caption of Fig. 2 for a full explanation of PLS results.

\section{The effects of temperature variables on the duration of leaf development and the infection rate of powdery mildew}

We found both the duration of leaf development and the infection rate of powdery mildew were affected by the mean temperatures (Tmean) and temperature differences (TD) of same periods, through investigating the relationship between the two temperature variables and the duration of leaf maturation, and also the relationship between the two temperature variables and the infection rate of powdery mildew by the PLS regression. We conducted the PLS regression on the 365 daily climatic variables of mean temperatures (Tmean) and temperature differences (TD) between previous April and March to the average duration of leaf maturation which worked as the dependent variable. The root means square error (RMSE) for the PLS models are $1.81 \%$ for Tmean and $2.04 \%$ for temperature difference, which indicated that the models fitted well for the data.

The PLS results of the two temperature variables and the duration of leaf maturation showed that mean temperature and daily temperature difference had a similar effect on the duration of leaf maturation at refoliation. From the VIP and standardized model coefficients of the PLS regression results, we found that the daily mean temperature during $14 \mathrm{Dec}-30 \mathrm{Dec}$ had a significant positive effect, while the daily temperature during $11 \mathrm{Feb}-13 \mathrm{Mar}$ had a significant negative effect on the duration of leaf maturation (Fig. 3b). That means that higher temperatures during defoliation period slowed down subsequent leaf growth, whereas high temperature during refoliation accelerated it. Results were similar for the daily temperature difference, but with a longer period of influence during defoliation (23 Nov - 20 Jan) and a slight delay in the influence period at refoliation (13 Feb - 15 Mar) (Fig. 3c). In our previous study, we found increasing the mean temperature during $11 \mathrm{Dec}-24$ Jan and the temperature differences during 6 Dec -11 Jan resulted in a higher infection rate of powdery mildew, while increasing the mean temperature during 6 Feb - 10 Mar and the temperature differences during 23 Jan - 30 Mar resulted in 
lower infection rate (Fig. 2d, and Fig.3 of Zhai et al., under review). We found the mean temperature during $14 \mathrm{Dec}-30 \mathrm{Dec}$ and during $11 \mathrm{Feb}-10 \mathrm{Mar}$ and the temperature differences during $6 \mathrm{Dec}-20$ Dec and during $13 \mathrm{Feb}-15$ Mar significantly affected both the duration of leaf maturation and infection rate of powdery mildew. Combined the results of the variation partitioning analysis which found Tmean1, Tmean2, and TD1 significantly affected the infection rate of powdery mildew, we kept the mean temperature during $14 \mathrm{Dec}-30 \mathrm{Dec}$ and during $11 \mathrm{Feb}-10 \mathrm{Mar}$, and temperature differences during during 6 Dec - 20 Dec the critical periods.

We then further plotted the duration of leaf maturation (the duration from copper brown to leaf aging) as a function of mean temperature during the two identified periods (during $14 \mathrm{Dec}-30 \mathrm{Dec}$ and during 11 Feb - 10 Mar), which clearly showed that the longer duration of leaf maturation was mainly responding to the higher mean temperatures during winter (Fig. 4). Warming during $14 \mathrm{Dec}-30 \mathrm{Dec}$ lengthened the duration of leaf maturation by 4.6 days $/{ }^{\circ} \mathrm{C}(p=0.05$, Fig. 5 a), although the warming trend of mean temperature during $14 \mathrm{Dec}-30 \mathrm{Dec}$ during 2003- 2011 was not significant $(p=0.16)$ and warming trend of duration of leaf maturation was also not significant ( $p=0.38$, Fig. S2). The positive relationship between the duration of leaf maturation and the mean temperature during $14 \mathrm{Dec}-30 \mathrm{Dec}$ was consistent with our findings from the Kriging interpolation (Fig. 4). The increasing of the duration of leaf maturation increased the infection rate of powdery mildew by $1.5 \%$ per day, which agreed with the PLS results in Fig. $2(p<0.01$, Fig. 5b).

Fig. 4 Response of duration from copper brown to leaf aging to daily mean temperature during 14 Dec- 30 Dec and during $11 \mathrm{Feb}-10 \mathrm{Mar}$. Variation in color reflects variation in duration from copper brown to leaf aging, while the black dots indicate duration from copper brown to leaf aging of each year during 2003-2011. The slopes of the contour lines show the relative importance of impacts of temperature increases during $14 \mathrm{Dec}-30 \mathrm{Dec}$ and during $11 \mathrm{Feb}-10$ Mar on the duration from copper brown to leaf aging.

Fig. 5 Relationship between duration from copper brown to leaf aging and mean temperature during 14 Dec- 30 Dec (a), and relationship between infection rate of powdery mildew and duration from copper brown to leaf aging (b). Trends are significant with $* p<0.05$ or $* * p<0.01$.

\section{Discussion}

This study built on previous results identifying critical influencing temperature periods in both the leaf fall and refoliation stages as drivers of subsequent powdery mildew infection rate of rubber leaves (Zhai et al., under review). We went further by providing the most comprehensive quantification of all the relevant factors to investigate the relationships between these factors and the powdery mildew infection by the PLS approach. Our results clearly showed that the powdery mildew infection was mainly affected by the extrinsic factor of winter temperature and intrinsic factor of duration of leaf maturation. Most of previous studies on the forecasting of powdery mildew disease have focused on the single effects of either the timing of phenologies, duration of leaf development between the phenological stages, or the climatic 
variables (PPRI, 1985; Shao and Hu, 1984; Yu et al., 1980; Yu et al., 1985; Zhang et al., 2009). Our results clearly quantified that the joint effects of the two most important factors explained more than $50 \%$ of the variations in the infection rate of powdery mildew (Fig. 3). The highly joint and undisentangled effects of temperature variables and duration of leaf maturation indicated that the powdery mildew infection is strongly influenced by both extrinsic and intrinsic factors, as that found for oak trees which are highly affected by the winter temperature and phenology (Marcais and Desprez-Loustau, 2014; Marcais et al., 2017). The study on rubber trees showed the infection of powdery mildew varied with rubber clones (Fang et al., 2013; Liyanage et al., 2019), and the species dependence of oak trees to the infection of powdery mildew was also detected (Marcais and Desprez-Loustau, 2014; Marcais et al., 2017). We assumed that the response variations between rubber clones might relate to rubber phenologies (both defoliation and refoliation phenologies), with different sensitivity to winter temperature (Fig. 4 \& Fig. 5c).

Our results in this study provided by far the most comprehensive evaluations of all phenology related factors on the infection rate of powdery mildew. In the current research, based on more precise daily data, we found the delay of the leaf emergence ( $5 \%$ leaves at copper brown stage) decreased the infection rate of powdery mildew. Conversely, the delay of the peak leaf expansion (light green stage) and peak of leaf aging increased the infection rate, and almost all the duration of leaf development showed a significant positive effect on the infection rate (Fig. 2). Our PLS results indicated that the duration of leaf development, rather than their timing was more important. This was confirmed by the variation partitioning analysis. Such results of the importances of duration of leaf development were consistent with the findings of Yu et al. (1980) on powdery mildew but also to that of Guyot et al. (2008) on another important rubber leaf disease, the South American Leaf Blight (Guyot et al., 2008). The prolonged duration of leaf development meant a slower leaf maturation making them more vulnerable to be infected which has been found to relate to the leaf trait (Pearse and Karban, 2013). The year of 2008 with the severest powdery mildew infection was found with a higher mean temperature during defoliation (1430 December) that resulted in a longer duration of leaf maturation (Fig. 5), although the leaf flushed earlier compared to other years (Zhai et al., 2019). This particular year confirmed that the timing of budburst is not as important as the leaf development rate. Less than 40 days of duration from copper brown to leaf aging would lead to an infection rate lower than 35\% (Fig. 4), which indicates that the duration of leaf maturation (from copper brown to leaf aging) could be used as an indicator for forecasting the powdery mildew infection. Therefore, the temperature during $14 \mathrm{Dec}-30 \mathrm{Dec}$ is highly recommended to be monitored as an early warning for the powdery mildew disease.

About one fourth of the variation in the infection rate of powdery mildew was left unexplained which could possibly be related to the duration of defoliation, which positively affected the powdery mildew infection (Yu et al., 1980). However, due to lack the data of defoliation dynamics, we could not test it directly in this study. However, we found a critical role of winter temperature to the infection rate of rubber powdery mildew in spring, which might relate to the higher temperature in winter increased the duration of defoliation (Yu et al., 1980). The findings that warmer winter temperatures increased the infection rate might relate to increase the duration of both defoliation and refoliation phenological periods (Fig. 5). Warmer winter temperature increased the duration of defoliation, leaving more overwinter leaves which 
were the sources of inoculum of next spring (Yu et al., 1980; Yu et al., 1985). To control the rubber leaf disease of Colletorichum and reduce the inoculum on the overwinter leaves, Guyot et al. (2001) recommended to use artificial defoliation and this approach has also been highly recommended to control the powdery mildew disease in China (Yu and Wang, 1988; Yu et al., 1980; Yu et al., 1985).

Our results indicated that the growers in marginal rubber growing region will experience increasing infection rates of powdery mildew if the winter warming is significant in the future, as forecasted by several climate models (Zomer et al., 2014). That may reduce the planters' incomes and also induce higher inputs of fungicide which may be detrimental for the environment. Therefore, rubber clones with faster leaf development rate would be highly recommended for future cultivar breeding and rubber industry sustainability.

\section{Conclusion}

From this study, our understanding of the complex factors influencing the infection rate of powdery mildew of rubber trees is significantly improved. We found that winter temperature had a controlling influence on the infection rate of powdery mildew. The second most important factor was the duration of leaf maturation. Both the extrinsic factor of winter temperature and intrinsic factor of duration of leaf maturation were critical influencing factors of powdery mildew infection. The future studies on the winter phenology (leaf fall dynamics) and subsequent powdery mildew infection will improve our understandings of the epidemiological features of the powdery mildew disease in tropical China, and provide scientific knowledge if it is introduced to other rubber development regions. These efforts can also help us to predict rubber powdery mildew in response to climate changes now and in the future, as well as predicting the future ecological and economic consequences.

\section{Declarations}

Acknowledgements

The authors would like to thank Dr. Wang Jing from East China Normal University for her helps on revising figures and for her great supports in performing the VPA analysis.

\section{Funding}

This work was financially supported by the National Natural Science Foundation of China (NSFC) and the Belmont Forum Collaborative Research Action "Mountains as Sentinels of Change -2015" (No. 41661144001), and also by the Key Research Program of Frontier Sciences, the Chinese Academy of Sciences (QYZDY-SSW-SMC014). This work is also supported by a visiting scholar grant to Deli Zhai to the University of Northern Arizona in 2017-2018 from the Kunming Institute of Botany. The funding bodies had no roles in the design of the study and collection, analysis, and interpretation of data and in writing the manuscript. 
DLZ and JCX conceived and designed the research. PT and YQL critically revised the manuscript and contributed to the interpretation and discussion of the results. DLZ perfomed data analysis, data interpretation, and wrote the paper. All authors discussed, revised, and approved the final manuscript.

Ethics approval and consent to participate

Not applicable.

Consent for publication

Not applicable.

Competing interests

The authors declare that they have no competing interests.

Open Access

This article is distributed under the terms of the Creative Commons Attribution 4.0 International License (http://creativecommons.org/licenses/by/4.0/), which permits unrestricted use, distribution, and reproduction in any medium, provided you give appropriate credit to the original author(s) and the source, provide a link to the Creative Commons license, and indicate if changes were made. The Creative Commons Public Domain Dedication waiver (http://creativecommons.org/publicdomain/zero/1.0/) applies to the data made available in this article, unless otherwise stated.

Additional files

Fig. S1 The location of study site (the rubber distribution in XSBN, and the location of Jinghong state farm)

Fig. S2 The trends of the (a) daily mean temperature during $14 \mathrm{Dec}-30 \mathrm{Dec}$ and the trends of duration from copper brown to leaf aging (b).

\section{References}

Cao, M., Zou, X.M., Warren, M. and Zhu, H., 2006. Tropical forests of Xishuangbanna, China. Biotropica, 38(3): 306-309.

Dixon, P., 2003. VEGAN, a package of R functions for community ecology. Journal of Vegetation Science, 14(6): 927-930.

Fang, J. et al., 2013. Resistance identification to powdery mildew of various rubber tree clones. Guangdong Agricultural Sciences(15): 88-90. 
Guo, L., Dai, J., Ranjitkar, S., Xu, J. and Luedeling, E., 2013. Response of chestnut phenology in China to climate variation and change. Agricultural and Forest Meteorology, 180: 164-172.

Guyot, J., Cilas, C. and Sache, I., 2008. Influence of host resistance and phenology on South American leaf blight of the rubber tree with special consideration of temporal dynamics. European Journal of Plant Pathology, 120(2): 111-124.

Guyot, J., Omanda EN, Ndoutoume A, Otsaghe AAM, Enjalric F, Assoumou HGN., 2001. Effect of controlling Colletotrichum leaf fall of rubber tree on epidemic development and rubber production. Crop Protection, 20(7): 581-590.

Li, Y.W., Xia YJ, Li HY, Deng XB, Sha LQ, Li B, Lin LX, Cao M., 2016. Accumulated Impacts of Sulfur Spraying on Soil Nutrient Availability and Microbial Biomass in Rubber Plantations. Clean-Soil Air Water, 44(8): 1001-1010.

Liyanage, K.K., Khan S, Brooks S, Mortimer PE, Karunarathna SC, Xu JC, Hyde KD., 2018. MorphoMolecular Characterization of Two Ampelomyces spp. (Pleosporales) Strains Mycoparasites of Powdery Mildew of Hevea brasiliensis. Frontiers in Microbiology, 9.

Liyanage, K.K., Khan S, Ranjitkar S, Yu H, Xu J, Brooks S, Beckschäfer P, Hyde KD., 2019. Evaluation of key meteorological determinants of wintering and flowering patterns of five rubber clones in Xishuangbanna, Yunnan, China. International Journal of Biometeorology 63:617-625.

Luedeling, E., 2017. chillR: Statistical Methods for Phenology Analysis in Temperate Fruit Trees., R Package Version 0.66. , http://cran.r-project.org/package=chillR.

Luedeling, E. and Gassner, A., 2012. Partial Least Squares Regression for analyzing walnut phenology in California. Agricultural and Forest Meteorology, 158-159: 43-52.

Marcais, B. and Desprez-Loustau, M.L., 2014. European oak powdery mildew: impact on trees, effects of environmental factors, and potential effects of climate change. Annals of Forest Science, 71(6): 633-642.

Marcais, B., Piou, D., Dezette, D. and Desprez-Loustau, M.L., 2017. Can Oak Powdery Mildew Severity be Explained by Indirect Effects of Climate on the Composition of the Erysiphe Pathogenic Complex? Phytopathology, 107(5): 570-579.

Mevik, B.H., Wehrens, R. and Liland, K., 2016. PLS: Partial Least Squares and Principal Component Regression., R Package Version 2.6.0, http://cran.r-project.org/package=pls.

Pearse, I.S. and Karban, R., 2013. Leaf drop affects herbivory in oaks. Oecologia, 173(3): 925-932.

PPRI, S., 1985. Rubber Powdery Mildew Forecasting in 1960-1980. Chinese Journal of Tropical Crop Research, 6(02): 51-56. 
Priyadarshan, P., 2011. Biology of Hevea rubber. CABI.

Shao, Z. and Hu, Z., 1984. Powdery Mildew infestation investigation on different leaf phenologies of rubber trees. Yunnan Tropical Technology, 1(01): 1-5.

Xiao, C., 2010. Comparative studies of comprehensive prevention and control for rubber powdery mildew. China Tropical Agriculture(06): 56-58.

$\mathrm{Yu}, \mathrm{H}$. et al., 2014. Greater diurnal temperature difference, an overlooked but important climatic driver of rubber yield. Industrial Crops and Products, 62(0): 14-21.

Yu, Z. and Wang, S., 1988. Epidemic processes and structure of rubber powdery mildew. Chinese Journal of Tropical Crops, 9(01): 83-89.

Yu, Z., Wang, S. and Zhou, C., 1980. Rubber powdery mildew epidemic factors and control analysis, and the assessment in 1979. Chinese Journal of Tropical Agriculture Research(02): 89-99.

Yu, Z., Wang, S., Zhou, C., Zheng, F. and Lin, S., 1985. Forecasting models of Rubber Powdery Mildew. Chinese Journal of Tropical Crops(02): 57-66.

Zhai, D.-L., Yu, H., Chen, S.-C., Ranjitkar, S. and Xu, J., 2019. Responses of rubber leaf phenology to climatic variations in Southwest China. International Journal of Biometeorology 63:607-616..

Zhang, H., Yang, S., Li, W., Hu, Y. and Bai, X., 2009. Epidemic pattern of rubber powdery mildew in Dehong The 2009 annual conference of Yunnan tropical crops Xishuangbanna, Yunnan, China, pp. 12.

Zhang, J. and Cao, M., 1995. Tropical forest vegetation of Xishuangbanna, SW China and its secondary changes, with special reference to some problems in local nature conservation. Biological Conservation, 73(3): 229-238.

Zhu, H., Cao, M. and Hu, H.B., 2006. Geological history, flora, and vegetation of Xishuangbanna, southern Yunnan, China. Biotropica, 38(3): 310-317.

Zomer, R.J. Trabucco A, Wang M, Lang R, Chen H, Metzger MJ, Smajgl A, Beckschäfer P, Xu J., 2014. Environmental stratification to model climate change impacts on biodiversity and rubber production in Xishuangbanna, Yunnan, China. Biological Conservation, 170(0): 264-273.

\section{Figures}




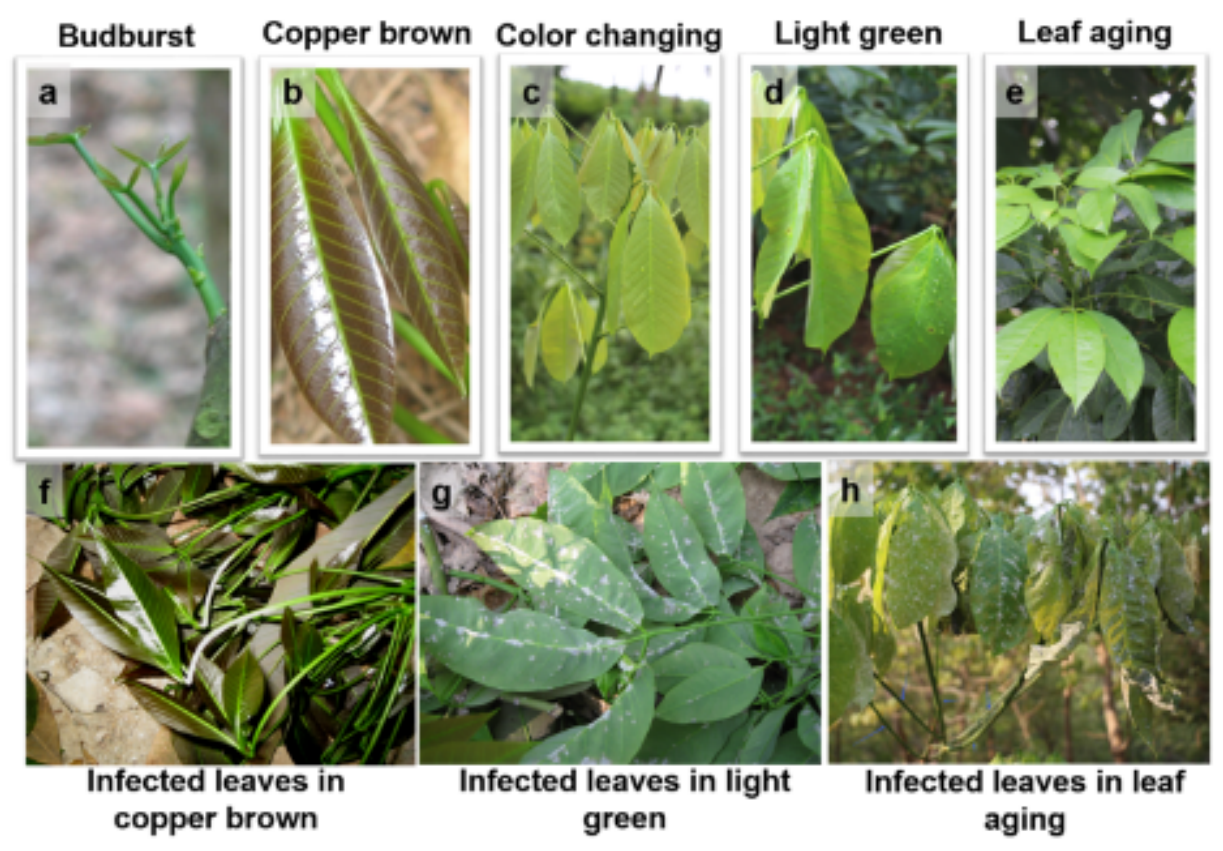

\section{Figure 1}

The five phenological phases of rubber trees in the refoliation season (a-d), and the leaves infected by powdery mildew disease

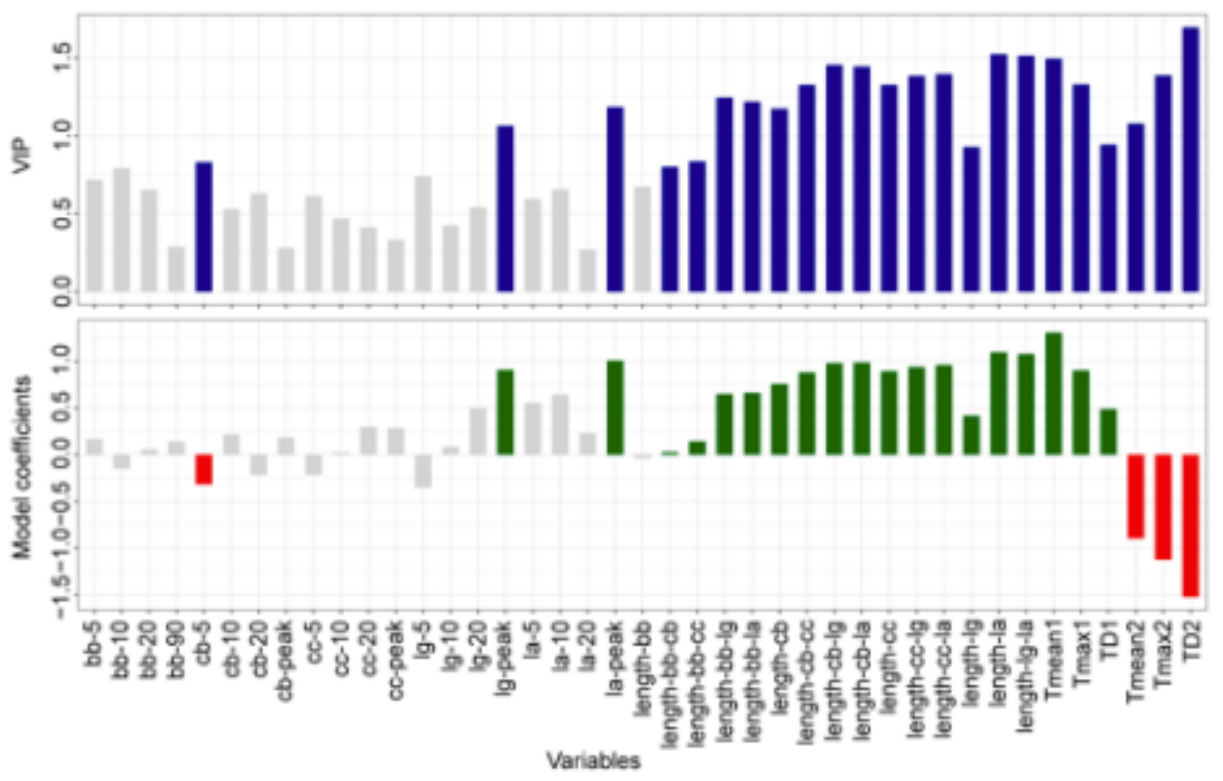

\section{Figure 2}

Results of Partial Least Squares (PLS) regression correlating infection rate of powdery mildew during 2003-2011 to fourty-one factors in three groups of timing of phenologies, duration of leaf development, and the climatic variables. In the upper panel, blue bars mean that VIP is above 0.8 , the threshold for variable importance. In the under panel, red bars correspond to important and negative model coefficients 
and VIP values are greater than 0.8 , while green bars indicate important positive relationships between infection rate of powdery mildew and the gray bars indicate no statistical significance.
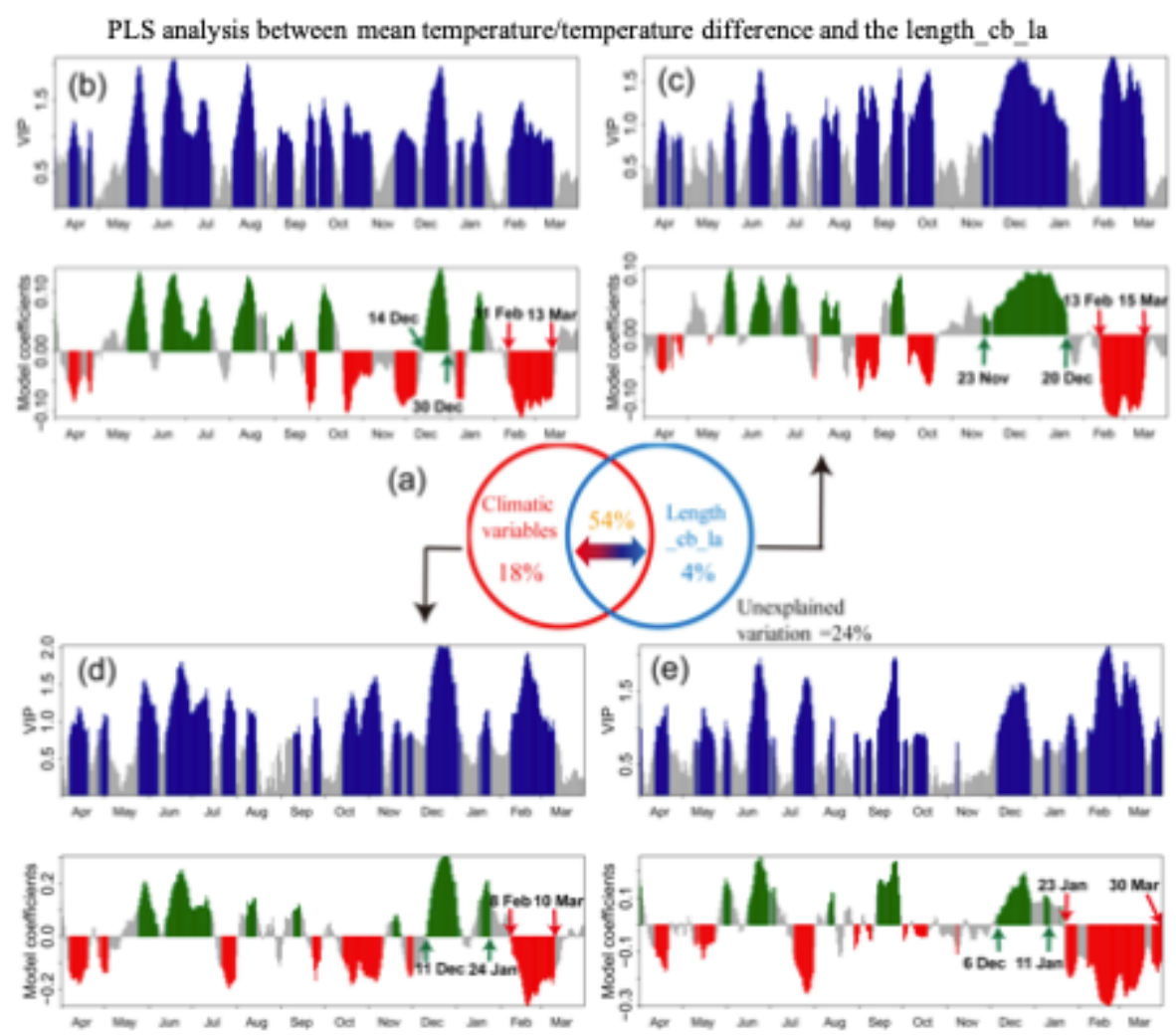

PLS analysis between mean temperature/temperature difference and the infection rate of powdery mildew

\section{Figure 3}

Variation partition analysis of the effects of timing of phenologies, duration of leaf development, and the climatic variables on the infection rate of powdery mildew (a), and the PLS results between (b) daily mean temperature, and (c) daily temperature difference from previous April to March and duration of leaf development ( from copper brown to leaf aging (length_cb_la)), and also the PLS results between (d) daily mean temperature, and (e) daily temperature difference and infection rate of powdery mildew during 2003-2011. See caption of Fig. 2 for a full explanation of PLS results. 


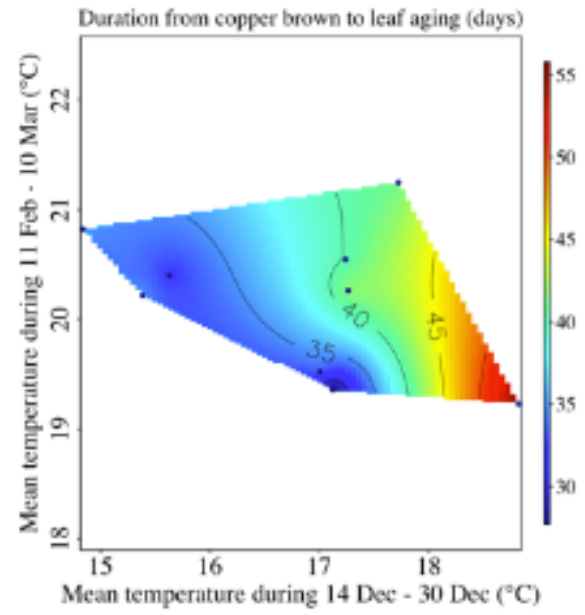

Figure 4

Response of duration from copper brown to leaf aging to daily mean temperature during $14 \mathrm{Dec}-30 \mathrm{Dec}$ and during $11 \mathrm{Feb}-10$ Mar. Variation in color reflects variation in duration from copper brown to leaf aging, while the black dots indicate duration from copper brown to leaf aging of each year during 20032011. The slopes of the contour lines show the relative importance of impacts of temperature increases during 14 Dec- 30 Dec and during 11 Feb - 10 Mar on the duration from copper brown to leaf aging.
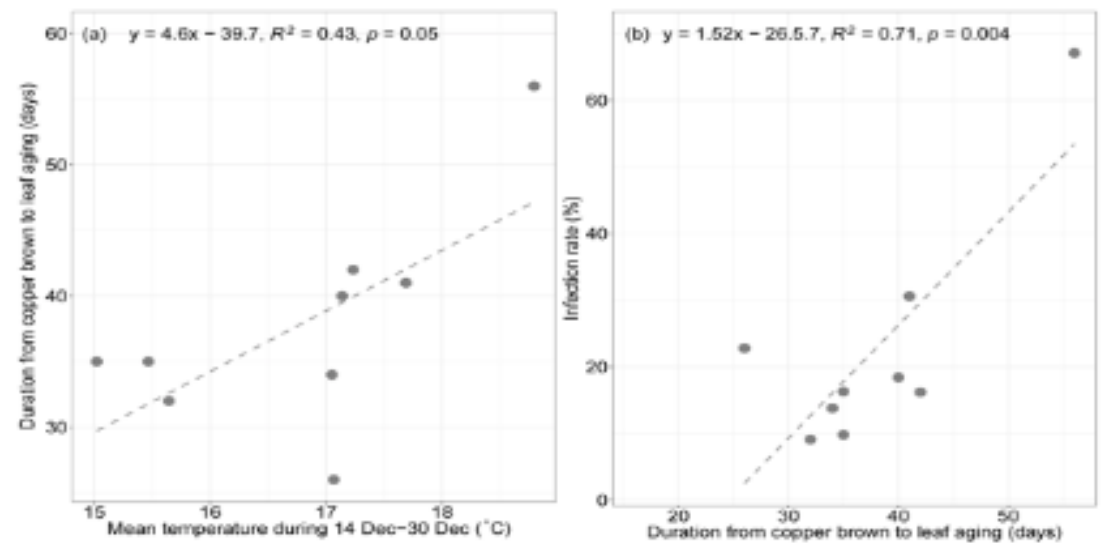

\section{Figure 5}

Relationship between duration from copper brown to leaf aging and mean temperature during 14 Dec- 30 Dec (a), and relationship between infection rate of powdery mildew and duration from copper brown to leaf aging (b). Trends are significant with ${ }^{*} p<0.05,{ }^{*} \mathrm{p}<0.01$.

\section{Supplementary Files}

This is a list of supplementary files associated with this preprint. Click to download. 
- Supplement.docx

Page 17/17 